\title{
Magnitude and Associated Risk Factor of HBV Virus Among Pregnant Mothers Attending Antenatal Care in Debre Tabor Referral Hospital; Northwest Ethiopia
}

\author{
Moges Ayalew Kassaw ${ }^{1, ~ *, ~ E n i n u r ~ D e j e n ~ A m e r a ~}{ }^{2}$, Kefyalew Amogne Azanaw ${ }^{3}$ \\ ${ }^{1}$ Department of Medical Laboratory Sciences, Debre Tabor Health Science College, Debre Tabor, Ethiopia \\ ${ }^{2}$ Department of Medical Laboratory Sciences, College Medicine and Health Sciences, Debre Tabor University, Debre Tabor, Ethiopia \\ ${ }^{3}$ Department of Nursing, Debre Tabor Health Science College, Debre Tabor, Ethiopia
}

Email address:

amoges@ymail.com (M. A. Kassaw), eninurdejen4@gmail.com (E. D. Amera), kefyalewamogne@gmail.com (K. A. Azanaw)

${ }^{*}$ Corresponding author

\section{To cite this article:}

Moges Ayalew Kassaw, Eninur Dejen Amera, Kefyalew Amogne Azanaw. Magnitude and Associated Risk Factor of HBV Virus Among Pregnant Mothers Attending Antenatal Care in Debre Tabor Referral Hospital; Northwest Ethiopia. Journal of Cancer Treatment and Research. Vol. 9, No. 1, 2021, pp. 1-9. doi: 10.11648/j.jctr.20210901.11

Received: October 26, 2020; Accepted: December 28, 2020; Published: March 10, 2021

\begin{abstract}
Background: Hepatitis is a contagious liver disease caused by Hepatitis B virus. When a pregnant mother infected, the Hepatitis B virus can stay in the body and Vertical transmit to baby and develop chronic liver disease. In regarding to this Neonatal immunization interrupts this vertical transmission and used to take preventive action. For that reason, this study was undertaken with the aim of determine the magnitude and predisposing factors of HBV infections among pregnant women. An institutional based cross-sectional study was conducted 333 pregnant women attending ANC from September 2020 to November 2020 at Debre Tabor Referral Hospital antenatal care clinic. Appropriate sample was collected; serum separated and tested with ELISA test for the detection of HBsAg. Fishers exact test was employed to see the association between variables as well as Logistic regression were applied to identify potential risk factors (P-value $<0.05)$ was considered as statistically significant. A total of 333 pregnant women within $100 \%$ response rate; were enrolled in this study and the magnitude of HBV infections found to be were (22.2\%). among the potential risk factors multiple sexual behavior (AOR 3.096), 95\% CI=1.469-6.525, $P$-value $=0.003$ ), shaving habit (AOR 3.375, 95\% CI=1.511-7.538, $P$-value $=0.003$ ), a history of needle stick injury (AOR 4.080, 95\% CI=2.0418.156, $P$-value $=0.000$ ), history of common usage of Sharpe materials (AOR 8.229, 95\% CI $=3.991-16.967, P$-value $=0.000)$ and history of home delivery by traditional attendants were (AOR $1.557,95 \% \mathrm{CI}=0.621-3.899, P$-value $=0.000$ ) were significantly associated with important predictors of hepatitis B infection. For that reason this study showed high endemicity of HBV infection among pregnant women. Multiple sexual practices, history of home delivery, needle stick injury, common usage of Sharpe materials and shaving habit were major factors for hepatitis B virus transmission. Thus, scaling up of screening pregnant women for HBV infection and provision of health education about risk factors and testing all pregnant mothers for hepatitis $\mathrm{B}$ virus should be a regular feature of the ANC service. Other community studies, as well as screening HBV antigen marker conducting, will play an important role in accurately determining the true spread of hepatitis B virus in the general population.
\end{abstract}

Keywords: HBV, Pregnancy, Magnitude, Risk Factor

\section{Background}

Hepatitis B virus (HBV) infection is an important worldwide public health problem and it is the most common cause of chronic infection can lead to liver cirrhosis and hepatocellular carcinoma [1-3]. It also known as serum hepatitis is a disease of the liver caused by hepatitis B virus group under Heapadnaviridae in which a core antigen surrounded by a shell containing hepatitis B surface antigen has numerous antigenic components which is reported to be the main etiological factor of chronic liver diseases worldwide [4-6]. The virus has 50-100 and 10 times infectious than immunodeficiency virus and hepatitis $\mathrm{C}$ virus respectively $[7,8]$. 
In Italy, HBV infection is endemic; approximately 400,000 infection (700/1000) were found per year [9]. During pregnancy $\mathrm{HBV}$ is associated with a high risk of maternal complications, has a high rate of vertical transmission causing foetal and neonatal hepatitis and has been reported as a leading cause of maternal mortality [10]. In accordance of world health organization, the saddle of HBV infection to be approximately 2 billion, $>350$ million chronically infected with HBV, and $500,000-700,000$ patients die annually as a result of HBV related liver disease, such as liver cirrhosis, heapatocellular carcinoma and the third most common cause of death in medical ward with $15-60 \%$ seropositivity of $\mathrm{HBsAg}[11,12]$.

Hepatitis is an inflammation of the liver characterized by the presence of inflammatory cells in the tissue of the organ and associated with high risk of fetal neonatal hepatitis maternal complication, jaundice in pregnancy and mortality during pregnancy and it referred to as silent killer $[13,14]$. Viral hepatitis at some stage in pregnancy is closely related to high risks of maternal complications including premature contractions, placenta Previa, and preterm delivery, premature rupture of membranes, vaginal bleeding, preterm labour and mortality with a high rate of vertical transmission and risk of transmitting infection to their newborn infants leading to fetal and neonatal hepatitis $[4,15]$.

In addition, the virus transmitted horizontally by means of sexual intercourse, exchange or transfer of body fluids like blood or saliva, needle sharing with drug addicts, tattooing, contact with persons with jaundice, dental procedures and blood transfusions [16].

However, the prevalence of HBV infection varies widely in different parts of the world [17]. According to this we can classify the prevalence as high (more than $8 \%$ ), medium (between $2 \%$ and $8 \%$ ), and low epidemic (less than $2 \%$ ) [1, 18]. For instance, the research conducted in different country in the world showed that there were high prevalence of HBV among pregnant mothers (in Paraná State, Brazil and Gambia $(18.5 \%$ and $9.2 \%)[2,19]$.

When we see about the prevalence in different parts of Ethiopia, Italy, Mbarara Regional Referral Hospital and Maranhão state Brazil indicated that there were moderate prevalence of HBV among pregnant mothers (Dessie town 4.9\% [3], Bahir Dar city 3.8\% [20], Arba Minch 4.3\% [21], and $5.4 \%$ in public hospitals in Ethiopia [22], 2.4\% [9], 3.12\% [23] and 7.4\% [1] respectively. In some parts of the world like Nepal $(0.25 \%)$ [24] and Espírito Santo State, Brazil (1.1\%) have lower prevalence of HBV infection among pregnant women [18].

In Ethiopia Various studies showed that blood transfusion, body tattooing, history of surgery and unsafe injection, history of abortion, most sexual partners', harmful practices associated with culture, such as ear pricing and also perinatal, horizontal, and sexual transmission is an important source of HBV transmission $[25,26]$. In Ethiopia the surveillance conducted from July to September, 2014 Hepatitis B virus infection and risk factors among pregnant women at public hospital showed that Pregnant women with hepatitis B virus infection are reservoir for the virus and do have high potential to transmit it to their fetuses (newborns) and the risk of HBV transmission to newborn infants accounts $70-90 \%$ during the simultaneous positivity of mothers with HBsAg seromarkers and $10-40 \%$ of risk of HBV transmission observed if mothers test positive for only HBV [22]. Viral hepatitis is blood borne pathogens can cause a life-threatening liver disease has important public health issue in developing countries including Ethiopia have intermediate endemicity (4.4\%) of HBV infection in pregnant women and contagious relatively easy to be transmitted from one infected individual to another by blood to blood contact, during birth, unprotected sex, and by sharing needles $[15,27]$ in regarding to this WHO recommended that hepatitis B vaccine be incorporated into routine infant and childhood immunization program for all countries by 1997such data are fundamental for health planers and care givers for evidencebased intervention [26].

Now a day's burden of hepatitis B in pregnant mother is one of the main problem for maternal health especially in Ethiopia [28]. Although many studies have been done on liver disease in different parts of Ethiopia, studies have shown that the spread of liver disease in people with lung cancer, HIV, heart disease, and diabetes. These are just a few of the studies that have been done on pregnant women.

So conducting this study has its own input for maternal health as well as for health program managers and for future study.

In addition, determining the prevalence of $\mathrm{HBV}$, the associated factors also, important to establish a strategy to prevent or reduce exposures, to devise a protocol for management of such exposures including post exposure management, Vaccination and draw the attention of stake holders to focus on such preventable but life threatening virus.

\section{Methods}

\subsection{Study Design and Setting}

A cross-sectional study was conducted from September 2020 to November 2020 at Debre Tabor Referral Hospital antenatal care clinic. The Hospital provides health service to three million inhabitants and residents found in Debre Tabor City, South Gondar administration zone, Amhara National Regional state, $666 \mathrm{~km}$ North of Addis Ababa.

\subsection{Study Subjects and Sampling}

All pregnant women who were visited ANC service in Debre Tabor General Hospital during study period are the study subject and Systematic random sampling method was used to select the study participants among ANC attendants.

On average, 20 pregnant women per day visited the ANC clinic at Debre Tabor Referral Hospital and there are 22 working days in a month excluding the National calendar days. Considering 3 months study period, 1320 pregnant women were expected to visit the ANC clinic during the study period. Hence, $\mathrm{K}$ is equal to four (4), one woman was randomly selected among ANC attendants by lottery method, and then every four (4) woman was selected to participate in the study.

\subsection{Sample Size Determination}

Sample size was determined using a previous study done 
in Gondar Health Center, northwest Ethiopian on Prevalence of hepatitis B virus in pregnant women was 7.3\% [29]. The minimum sample size was calculated using a single population formula, taking into account the $7.3 \%$ prevalence of HBV in Gondar Health center sero-positive of pregnant women with $3 \%$ margin error and $95 \%$ confidence interval (CI), the sample size was determined to be 333 .

$$
\mathrm{n}=\frac{z^{2} \alpha / 2(P(1-P))}{d^{2}}
$$

$\mathrm{n}=$ the minimum sample size

$\mathrm{z}=$ the standard normal deviate $=1.96$

$\mathrm{p}=$ the proportion in the target population estimated to have a particular characteristic in which previous prevalence $7.3 \%$ [29]

$$
\mathrm{q}=1.0-\mathrm{p}=1-0.073=0.927
$$

$\mathrm{d}=$ Degree of accuracy desired which is $3 \%(0.03)$ consequently by applying the

Formula as follows

$$
\mathrm{n}=\frac{(1.96) 2 \times 0.073 \times(1-0.073)}{0.03^{2}}=\frac{3.8416 \times 0.073 \times 0.927}{0.0009}=289
$$

Considering the $15 \%$ non-response (attrition) on 289 is 29 then the minimum sample size for this study is $289+29=318$. But I have used a minimum sample size of 333 is chosen for this study.

\subsection{Sample Collection and Laboratory Analysis}

After obtaining written consent from the study subjects the trained nurses working at ANC clinic were assigned to collecte appropriate data, Essential information for this study was collected from the study participants orally and in writing questionnaires. After verification of test kits to determine the accuracy of known positive and negative samples, serum of this known sample was analyzed for HBsAg were confirmed by ELISA technique.

Then, venous blood was collected and serum was separated by centrifugation according to SOPS by trained medical laboratory specialist and tested for HBsAg using ELISA Hepanostica HBsAg Uniform II (Bio-Merieux, Boxtel, and Netherland) was screened.

\subsection{Quality Control and Data Analysis}

The principal investigator and supervisors was assigned to guide the data collection and check the data completeness, consistency of the questionnaire and based on test manufacture instruction the procedure was done by the following manner.

We strictly followed the standard operating procedures to insure the quality of laboratory results were followed during sample collection and laboratory investigation. Known positive and Negative sample for HBV sample were used and analyzed as internal quality control before the actual investigation. Besides this all laboratory analysis was performed according to manufacturer instruction.

Data was entered and analyzed using Statistical Package for Social Sciences (SPSS) version 20 tactical software. Fishier exact test, logistic regression and 95\% confidence interval were employed to determine association between possible variables. Also with P-value of $<0.05$ was regarded as significant.

\section{Result}

\subsection{Demographic Characteristics}

From September 2020 to November 2020, 333 pregnant women were selected for a study conducted on pregnant mothers attending antenatal care at Debre Tabor Referral Hospital the ANC Clinic.

The majority of the study participant lived in urban 210 $(63.1 \%)$ and of $240(72.1 \%)$ were orthodox, $133(39.9 \%)$ were the age range of $18-27$ years old, 157 (47.1\%) were employed and $256(85.9 \%)$ were secondary and above education level. The magnitude of HBV infection in sociodemographic states show that there were high prevalence in urban 48 (14.4\%), orthodox $42(12.6 \%)$, employed $30(9 \%)$ and with age range of $18-27$ had $26(7.8 \%)$ in related to which had low prevalence in other socio-demographic characteristics like the age of $>48$ years $6(1.8 \%)$ and day

\begin{tabular}{|c|c|c|c|c|}
\hline \multirow{2}{*}{ Variables } & & \multirow{2}{*}{ Frequency N (\%) } & \multicolumn{2}{|l|}{ HBV status } \\
\hline & & & Positive N (\%) & Negative N (\%) \\
\hline \multirow{4}{*}{ Age s } & $18-27$ & $133(39.9)$ & $26(7.8)$ & $107(32.1)$ \\
\hline & $28-37$ & $93(27.9)$ & $22(6.6)$ & $71(21.3)$ \\
\hline & $38-47$ & $87(26.1)$ & $20(6)$ & $67(20.1)$ \\
\hline & $>48$ & $20(6)$ & $6(1.8)$ & $14(4.2)$ \\
\hline \multirow{2}{*}{ Resident } & Urban & $210(63.1)$ & $48(14.4)$ & $162(48.6)$ \\
\hline & Rural & $123(36.9)$ & $26(7.8)$ & $97(29.1)$ \\
\hline \multirow{3}{*}{ Occupation } & Employed & $157(47.1)$ & $30(9)$ & $127(38.1)$ \\
\hline & House wife & $25(7.5)$ & $20(6)$ & $10(3)$ \\
\hline & Student & $121(36.3)$ & $13(3.9)$ & $108(32.4)$ \\
\hline \multirow{4}{*}{ Religion } & Orthodox & $240(72.1)$ & $42(12.6)$ & $198(59.5)$ \\
\hline & Muslim & $44(13.2)$ & $14(4.2)$ & $30(9)$ \\
\hline & Catholic & $27(8.1)$ & $12(3.6)$ & $15(4.5)$ \\
\hline & Others & $22(6.6)$ & $6(1.8)$ & $16(4.8)$ \\
\hline \multirow[b]{2}{*}{ Education status } & non formal education & $16(4.8)$ & $7(2.1)$ & $9(2.7)$ \\
\hline & Primary school & $31(9.3)$ & $15(4.5)$ & $16(4.8)$ \\
\hline
\end{tabular}
labors $11(3.3 \%)$ (Table 1).

Table 1. Socio-demogaphic and HBV states of pregnant women at Debre Tabor referral hospital, south Gondar, northwest, Ethiopia, 2020. (N=333). 


\subsection{Exposure to Potential Risk Factors of Explanatory Variables for Hepatitis $B$ Virus Infection}

Concerning to the exposure of potential risk factor of HBV infection, one hundred four $(21.2 \%)$ women's had a history of multiple sexual behavior, of them $35(10.5 \%)$ were HBV positive, $95(28.5 \%)$ were had a history of tattooing among this twenty five $(7.5 \%)$ were HBV positive, fifty one $(15.3 \%)$ had a history of abortion and 43 (12.9\%) of them were HBV positive, and $70(21 \%)$ pregnant women's had shaving habit among them 25 (7.5\%) were HBV positive, 119 (35.5\%) had need stick injury and $45(13.5 \%)$ were HBV positive. When we see other reasonable factors $70(21 \%)$ women who had a history of common sharing of tooth brush 16 (4.8\%) were HBV positive, one hundred sixty three $(83.4 \%)$ had been ear pricing of them $46(13.8 \%)$ were HBV positive, and 67 $(20.1 \%)$ had a history of surgery of them $22(6.6 \%)$ were HBV positive. On the other hand $105(31.5 \%)$ pregnant women delivered in their home among this $46(13.8 \%)$ were HBV positive, and $48(14.4 \%)$ had received blood transfusion of them $17(5.1 \%)$ were positive. In this study $169(50.7 \%)$ women were singled and $26(7.8 \%)$ of the were HBV positive because of this women who were single they had multiple sexual behavior and this is the main risk for women to exposed to hepatitis B infection (table 2).

Table 2. Explanatory variables and hepatitis B virus infection among pregnant women attending at Debre Tabor Referral Hospital, South Gondar, Northwest, and Ethiopia 2020. $(N=333)$.

\begin{tabular}{|c|c|c|c|c|}
\hline \multirow{2}{*}{ Variables } & & \multirow{2}{*}{ Total (N) } & \multicolumn{2}{|l|}{ Anti HBV status } \\
\hline & & & Positive N (\%) & Negative $\mathbf{N}(\%)$ \\
\hline \multirow{2}{*}{ Multiple sexual behaviour } & Yes & $104(21.2)$ & $35(10.5)$ & $69(20.7)$ \\
\hline & No & $229(68.8)$ & $(39(11.7)$ & $190(57.1)$ \\
\hline \multirow{2}{*}{ History of tattooing } & Yes & $95(28.5)$ & $25(7.5)$ & $70(21)$ \\
\hline & No & $238(71.5)$ & $49(14.7)$ & $189(56.8)$ \\
\hline \multirow{2}{*}{ History of abortion } & Yes & $51(15.3)$ & $43(12.9)$ & $8(2.4)$ \\
\hline & No & $282(84.7)$ & $31(9.3)$ & $251(75.4)$ \\
\hline \multirow{2}{*}{ shaving habit } & Yes & $70(21)$ & $25(7.5)$ & $45(13.5)$ \\
\hline & No & $263(79)$ & $49(14.7)$ & $214(64.3)$ \\
\hline \multirow{2}{*}{ Needle stick injury } & Yes & $119(35.7)$ & $45(13.5)$ & $74(22.2)$ \\
\hline & No & $214(64.3)$ & $29(8.7)$ & $185(55.6)$ \\
\hline \multirow{2}{*}{ Communal usage of sharp materials } & Yes & $104(31.2)$ & $49(14.7)$ & $55(16.5)$ \\
\hline & No & $229(68.8)$ & $25(7.5)$ & $204(61.3)$ \\
\hline \multirow{2}{*}{ Sharing of toothbrush } & Yes & $70(21)$ & $16(4.8)$ & $54(16.2)$ \\
\hline & No & $263(79)$ & $58(17.4)$ & $205(61.6)$ \\
\hline \multirow{2}{*}{ Ear pricing } & Yes & $163(83.4)$ & $46(13.8)$ & $117(35.1)$ \\
\hline & No & $170(60)$ & $28(8.4)$ & $142(42.6)$ \\
\hline \multirow{2}{*}{ History of surgery } & Yes & $67(20.1)$ & $22(6.6)$ & $45(13.5)$ \\
\hline & No & $266(79.9)$ & $52(15.6)$ & $214(64.3)$ \\
\hline \multirow{2}{*}{ History of hone delivery } & Yes & $105(31.5)$ & $46(13.8)$ & $59(17.7)$ \\
\hline & No & $228(68.5)$ & $28(8.4)$ & $200(60.1)$ \\
\hline \multirow{2}{*}{ History of blood transfusion } & Yes & $48(14.4)$ & $17(5.1)$ & $31(9.3)$ \\
\hline & No & $285(85.6)$ & $57(17.1)$ & $228(68.5)$ \\
\hline \multirow{4}{*}{ Marital status } & Single & $169(50.7)$ & $26(7.8)$ & $143(42.9)$ \\
\hline & Married & $106(31.8)$ & $21(6.3)$ & $85(25.5)$ \\
\hline & Divorced & $35(10.5)$ & $16(4.8)$ & $19(5.7)$ \\
\hline & Widowed & $23(6.9)$ & $11(3.3)$ & $12(3.6)$ \\
\hline
\end{tabular}

\subsection{Association of HBV Infection and Explanatory Variables Among Study Subjects in Bi-variate Logistic Analysis}

The association between HBV infection and risk factors were analyzed by using logistic regression and multivariate logistic regression analysis was used for scheming confounding factors and evaluate the strength association of variables with HBV infection among study group.

In Bi-variate logistic regression; variables (multiple sexual behavior, history of abortion, shaving habit, needle stick injury, common sharing of sharp materials, ear pricing, history of surgery, history of blood transfusion and home delivery) were associated to HBV infection ( $P$ value $<0.05$ ) in bi-variate analysis and they were entered to multivariate logistic regression (table 3 ). 
Table 3. Bi-variate logistic regression observation on risk factor association with HBV infection among pregnant women at Debre Tabor Referral Hospital, South Gondar, Northwest, Ethiopia 2020 (N=333).

\begin{tabular}{|c|c|c|c|c|c|c|}
\hline \multirow{2}{*}{ Variables } & & \multirow{2}{*}{ Total (N) } & \multicolumn{2}{|c|}{ Anti HBV status } & \multirow{2}{*}{ COR $(95 \% \mathrm{CI})$} & \multirow{2}{*}{ P-value } \\
\hline & & & Positive N (\%) & Negative N (\%) & & \\
\hline \multirow{2}{*}{$\begin{array}{l}\text { Multiple sexual } \\
\text { behaviour }\end{array}$} & Yes & $104(21.2)$ & $35(10.5)$ & $69(20.7)$ & $2.471(1.450-4.211)$ & 0.001 \\
\hline & No & $229(68.8)$ & 39 (11.7) & $190(57.1)$ & 1 & \\
\hline \multirow{2}{*}{ History of tattooing } & Yes & $95(28.5)$ & $25(7.5)$ & $70(21)$ & $1.378(0.791-2.398)$ & 0.257 \\
\hline & No & $238(71.5)$ & 49 (14.7) & $189(56.8)$ & 1 & \\
\hline \multirow{2}{*}{ History of abortion } & Yes & $19(5.7)$ & $12(3.6)$ & $7(2.1)$ & $6.968(2.634-18.430)$ & 0.000 \\
\hline & No & $314(94.3)$ & $62(18.6)$ & $252(75.4)$ & 1 & \\
\hline \multirow{2}{*}{ shaving habit } & Yes & $70(21)$ & $25(7.5)$ & $45(13.5)$ & $2.426(1.360-4.330)$ & 0.003 \\
\hline & No & $263(79)$ & 49 (14.7) & $214(64.3)$ & 1 & \\
\hline \multirow{2}{*}{ Needle stick injury } & Yes & $119(35.7)$ & $45(13.5)$ & $74(22.2)$ & $3.879(2.263-6.650)$ & 0.000 \\
\hline & No & $214(64.3)$ & $29(8.7)$ & $185(55.6)$ & 1 & \\
\hline \multirow{2}{*}{$\begin{array}{l}\text { Communal usage of } \\
\text { sharp materials }\end{array}$} & Yes & $104(31.2)$ & 49 (14.7) & $55(16.5)$ & $7.270(4.126-12.808)$ & 0.000 \\
\hline & No & $229(68.8)$ & $25(7.5)$ & $204(61.3)$ & 1 & \\
\hline \multirow{2}{*}{$\begin{array}{l}\text { Sharing of } \\
\text { toothbrush }\end{array}$} & Yes & $70(21)$ & $16(4.8)$ & $54(16.2)$ & $1.047(0.558-1.965)$ & 0.886 \\
\hline & No & $263(79)$ & $58(17.4)$ & $205(61.6)$ & 1 & \\
\hline \multirow{2}{*}{ Ear pricing } & Yes & $163(83.4)$ & $46(13.8)$ & $117(35.1)$ & $1.994(1.174-3.387)$ & 0.011 \\
\hline & No & $170(60)$ & $28(8.4)$ & $142(42.6)$ & 1 & \\
\hline \multirow{2}{*}{ History of surgery } & Yes & $67(20.1)$ & $22(6.6)$ & $45(13.5)$ & $2.012(1.112-3.641)$ & 0.021 \\
\hline & No & $266(79.9)$ & $52(15.6)$ & $214(64.3)$ & 1 & \\
\hline \multirow{2}{*}{$\begin{array}{l}\text { History of home } \\
\text { delivery }\end{array}$} & Yes & $105(31.5)$ & $46(13.8)$ & $59(17.7)$ & $5.569(3.206-9.675)$ & 0.000 \\
\hline & No & $228(68.5)$ & $28(8.4)$ & $200(60.1)$ & 1 & \\
\hline \multirow{2}{*}{$\begin{array}{l}\text { History of blood } \\
\text { transfusion }\end{array}$} & Yes & $48(14.4)$ & $17(5.1)$ & $31(9.3)$ & $2.194(1.135-4.239)$ & 0.019 \\
\hline & No & $285(85.6)$ & $57(17.1)$ & $228(68.5)$ & 1 & \\
\hline \multirow{4}{*}{ Marital status } & Single & $169(50.7)$ & $26(7.8)$ & $143(42.9)$ & 1 & \\
\hline & Married & $106(31.8)$ & $21(6.3)$ & $85(25.5)$ & $1.359(0.720-2.563)$ & 0.344 \\
\hline & Divorced & $35(10.5)$ & $16(4.8)$ & $19(5.7)$ & $4.632(2.112-10.159)$ & 0.000 \\
\hline & Widowed & $23(6.9)$ & $11(3.3)$ & $12(3.6)$ & $5.042(2.012-12.634)$ & 0.001 \\
\hline
\end{tabular}

\subsection{Association of HBV Infection and Potential Risk Factors Among Study Subjects in Multivariate Logistic Analysis}

In bivariate logistic regression; (multiple sexual behavior, history of abortion, shaving habit, needle stick injury, common sharing of sharp materials, ear pricing, history of surgery, history of blood transfusion and home delivery) were associated to $\mathrm{HBV}$ infection ( $\mathrm{P}$ value $<0.05$ ) in bivariate analysis and they were entered to multivariate logistic regression (table 3). In final model of multivariate logistic regression the same five variables were found to significant predictor of HBV infection ( $\mathrm{P}-$ value $<0.05$ ).

In relation to multiple sexual behavior, $21.2 \%$ of the study subjects were had multiple sexual behavior, of which $10.5 \%$ were found to be positive for HBsAg. Statistical significant association was observed between multiple sexual behavior and HBV infection $(P$-value $=0.003)$. Those who had multiple sexual behavior were 2.5 times more likely infected than their counterparts (AOR 3.096), 95\% CI=1.469-6.525).

Pregnant women who had shaving habit were $21 \%$, of which 7.5\% were found to be positive of HBsAg. Statistical significant association was detected between women had shaving habit and HBV infection $(P$-value $=0.003)$. Those who had shaving habit were 3.4 times more likely infected than women who had no shaving habit (AOR 3.375, 95\% $\mathrm{CI}=1.511-7.538$ ).

The proportion of pregnant women who had needle stick injury was $35.5 \%$, of which $13.5 \%$ were positive of HBsAg. Statistical significant association was obtained between women had needle stick injury and HBV infection $(P$ value $=0.000$ ). Who had needle stick injury were 4.1 times high risk to be infected by HBV infection than women who had no a history of needle stick injury (AOR 4.080, 95\% $\mathrm{CI}=2.041-8.156$ ).

Among 333 pregnant women, 104 women were had Communal usage of sharp materials, of these $16.5 \%$ were positive for HBV infection. Statistical significant association was perceived between these two variables $(P$-value $=0.000)$. Those women with history of common usage of Sharpe materials were 8.229 times more likely had HBV infection (AOR 8.229, 95\% CI=3.991-16.967).

Women who had a history of home delivery by traditional attendants were $105(31.5 \%)$, of which $46(13.8 \%)$ were HBsAg positive. Statistical significant association was sensed between women who delivered at home and HBV infection $(P$-value $=0.000)$. Those women with history of home delivery by traditional attendants were 2 times more likely infected with HBV infection (AOR 1.557, 95\% $\mathrm{CI}=0.621-3.899)$ (table 4). 
Moges Ayalew Kassaw et al:: Magnitude and Associated Risk Factor of HBV Virus Among Pregnant Mothers Attending Antenatal Care in Debre Tabor Referral Hospital; Northwest Ethiopia

Table 4. Multiple logistic regression observation on risk factor association with HBV infection among pregnant women at Debre Tabor Referral Hospital, South Gondar, Northwest, Ethiopia 2020. (N=333).

\begin{tabular}{|c|c|c|c|c|c|c|c|c|}
\hline \multirow{2}{*}{ Variables } & & \multirow{2}{*}{ Total (N) } & \multicolumn{2}{|c|}{ Anti HBV status } & \multirow{2}{*}{ COR $(95 \%$ CI) } & \multirow{2}{*}{ P-value } & \multirow{2}{*}{ AOR (95\% CI) } & \multirow{2}{*}{ P-value } \\
\hline & & & Positive N (\%) & Negative N (\%) & & & & \\
\hline \multirow{2}{*}{$\begin{array}{l}\text { Multiple sexual } \\
\text { behavior }\end{array}$} & Yes & $104(21.2)$ & $35(10.5)$ & $69(20.7)$ & $2.471(1.450-4.211)$ & 0.001 & $3.1(1.469-6.525)$ & $0.003^{*}$ \\
\hline & No & $229(68.8)$ & $39(11.7)$ & $190(57.1)$ & 1 & & 1 & \\
\hline \multirow{2}{*}{$\begin{array}{l}\text { History of } \\
\text { abortion }\end{array}$} & Yes & $19(5.7)$ & $12(3.6)$ & $7(2.1)$ & $\begin{array}{l}6.968(2.634- \\
18.430)\end{array}$ & 0.000 & $1.9(0.549-6.637)$ & 0.309 \\
\hline & No & $314(94.3)$ & $62(18.6)$ & $252(75.4)$ & 1 & & 1 & \\
\hline \multirow{2}{*}{ shaving habit } & Yes & $70(21)$ & $25(7.5)$ & $45(13.5)$ & $2.426(1.360-4.330)$ & 0.003 & $3.4(1.511-7.538)$ & $0.003 *$ \\
\hline & No & $263(79)$ & $49(14.7)$ & $214(64.3)$ & 1 & & 1 & \\
\hline \multirow{2}{*}{$\begin{array}{l}\text { Needle stick } \\
\text { injury }\end{array}$} & Yes & $119(35.7)$ & $45(13.5)$ & $74(22.2)$ & $3.879(2.263-6.650)$ & 0.000 & $4.1(2.041-8.156)$ & $0.000^{*}$ \\
\hline & No & $214(64.3)$ & $29(8.7)$ & $185(55.6)$ & 1 & & 1 & \\
\hline \multirow{2}{*}{$\begin{array}{l}\text { Communal usage } \\
\text { of sharp materials }\end{array}$} & Yes & $104(31.2)$ & $49(14.7)$ & $55(16.5)$ & $\begin{array}{l}7.270(4.126- \\
12.808)\end{array}$ & 0.000 & $8.2(3.991-16.967)$ & $0.000^{*}$ \\
\hline & No & $229(68.8)$ & $25(7.5)$ & $204(61.3)$ & 1 & & 1 & \\
\hline \multirow{2}{*}{ Ear pricing } & Yes & $163(83.4)$ & $46(13.8)$ & $117(35.1)$ & 1.994 (1.174-3.387) & 0.011 & $1.6(0.809-3.144)$ & 0.178 \\
\hline & No & $170(60)$ & $28(8.4)$ & $142(42.6)$ & 1 & & 1 & \\
\hline \multirow{2}{*}{ History of surgery } & Yes & $67(20.1)$ & $22(6.6)$ & $45(13.5)$ & $2.012(1.112-3.641)$ & 0.021 & $1.5(0.646-3.361)$ & 0.357 \\
\hline & No & $266(79.9)$ & $52(15.6)$ & $214(64.3)$ & 1 & & 1 & \\
\hline \multirow{2}{*}{$\begin{array}{l}\text { History of home } \\
\text { delivery }\end{array}$} & Yes & $105(31.5)$ & $46(13.8)$ & $59(17.7)$ & $5.569(3.206-9.675)$ & 0.000 & $6.8(3.332-13.820)$ & $0.000^{*}$ \\
\hline & No & $228(68.5)$ & $28(8.4)$ & $200(60.1)$ & 1 & & & \\
\hline \multirow{2}{*}{$\begin{array}{l}\text { History of blood } \\
\text { transfusion }\end{array}$} & Yes & $48(14.4)$ & $17(5.1)$ & $31(9.3)$ & $2.194(1.135-4.239)$ & 0.019 & $1.6(0.621-3.899)$ & 0.345 \\
\hline & No & $285(85.6)$ & $57(17.1)$ & $228(68.5)$ & 1 & & 1 & \\
\hline
\end{tabular}

\section{Discussion}

WHO classification of HBV infection classified as high $(>8)$, medium $(2-7)$ and low $(<2)$ and it remains a public health problem in the world that causes chronic infection affecting pregnant women ranging from sever to mothers and chronic infection to new borne [27]. In present study, sera collected from pregnant women were screened for $\mathrm{HBsAg}$ shows acute HBV infection. The prevalence of HBV among the present study participant $22.2 \%$.

The $22.2 \%$ prevalence of HBV infection obtained in the present study area appears to be high endemic according to WHO criteria of global HBV epidemiology.

The magnitude of Hepatitis B surface antigen in this study relatively higher than the study carried out in Iran $(0.7 \%)$ [30], Egypt (1.75\%) [31]. However, higher prevalence of Hepatitis B surface antigen were reported in Cameroon 7.7\% [8], Mali 8.0\% [32], Nigeria 9.3\% [33]. Other studies conducted in university of Ilorin teaching hospital in Nigeria on the similar study population showed that prevalence of hepatitis B virus infection was found to 41 $(5.6 \%)$ out 728 pregnant women at Omdurman Maternity Hospital in Sudan [14]. Globally, the incidence of liver disease varies from continent to continent, with more than $8 \%$ in Africa, Asia and the Western Pacific and the results from this study are in agreement with high $(>8 \%)$ in Southern and Eastern Europe and lowest $(<2 \%)$ in Western Europe, North America and Australia [6]. The magnitude of HBV infection (22.2\%) inline (high endemic in accordance of WHO criteria) with findings of similar studies conducted on pregnant women who attended antenatal clinics of the hospitals on other parts of the world revealed $10 \%$ in Hong Kong [18], 12\% in Taiwan
[34], $14.3 \%$ and $17.3 \%$ Nouna or Ouagadougou state in Burkina Faso [35] respectively.

In contrast to previous study conducted in different parts of Ethiopia, the present study (22.2\%) is also relatively high than studies carried out among pregnant women in Jimma and Bahir Dar city 3.7\% and 3.8\% [20,26] and Gondar town $7.3 \%$ [29] respectively.

In multivariate logistic regression, history of multiple sexual behavior, shaving habit, needle stick injury, common sharing of sharp materials, and home delivery were significant factors of Hepatitis B virus infection among pregnant women $(\mathrm{P}$ - value $>0.05)$ and supported by similar findings research done in Kano state of Nigeria [16].

On the other hand, mothers who undergo surgery and donated blood did not have a association with Hepatitis B virus, but compared to the finding in Kano State of Nigeria [16] and Egypt [31], those who undergo surgery and blood donations had significant association with HBV infection. The history of blood donation among pregnant mothers included in this study and the number of mothers who have undergone surgery have not been directly associated with HBV infection. Infectious diseases like HBV infection (liver disease) among the greatest threats to blood safety for transfusion recipients and pose a serious public health problem [36].

In this study, among the total study participants $21.2 \%$ of the study subjects were had multiple sexual behavior, of which $10.5 \%$ were found to be positive for HBsAg. Statistical significant association was observed between multiple sexual behavior and HBV infection (AOR 3.096), 95\% CI=1.469-6.525, $P$-value $=0.003)$. Those who had multiple sexual behavior were 3 times more likely infected than their counterparts.

Pregnant women who had shaving habit were $21 \%$, of which $7.5 \%$ were found to be positive of HBsAg. Statistical 
significant association was detected between women had shaving habit and HBV infection $(P$-value $=0.003)$. Those who had shaving habit were 3.4 times more likely infected than women who had no shaving habit (AOR 3.375, 95\% $\mathrm{CI}=1.511-7.538)$.

The proportion of pregnant women who had needle stick injury was $35.5 \%$, of which $13.5 \%$ were positive of HBsAg. Statistical significant association was obtained between women had needle stick injury and HBV infection $(P$ value $=0.000$ ). Women who had needle stick injury were 4.1 times high risk to be infected by HBV infection than women who had no a history of needle stick injury (AOR 4.080, 95\% $\mathrm{CI}=2.041-8.156)$.

Among 333 pregnant women, 104 women were had Communal usage of sharp materials, of these $16.5 \%$ were positive for HBV infection. Statistical significant association was perceived between these two variables $(P$-value $=0.000)$. Those women with history of common usage of Sharpe materials were 8.229 times more likely had HBV infection (AOR 8.229, 95\% CI=3.991-16.967).

Women who had a history of home delivery by traditional attendants were 105 (31.5\%), of which 46 (13.8\%) were HBsAg positive. Statistical significant association was sensed between women who delivered at home and HBV infection $(P$-value $=0.000)$. Those women with history of home delivery by traditional attendants were 2 times more likely infected with HBV infection (AOR 1.557, 95\% $\mathrm{CI}=0.621-3.899$ ).

\section{Conclusions}

This study showed high endemicity of HBV infection among pregnant women. Multiple sexual practices, history of home delivery, needle stick injury, common usage of Sharpe materials and shaving habit were found to be significant predictors of HBV infection. Thus, scaling up of screening pregnant women for HBV infection and provision of health education about risk factors, mode of transmission should be recommended and testing all pregnant mothers for hepatitis B virus should be a regular feature of the ANC service. In addition, other communitybased studies and screening HBV antigen marker conducting, may be used to identify potential transmission routes of hepatitis B virus and to take preventive action. Other community studies, will play an important role in accurately determining the true spread.

\section{Recommendation}

Protective measures for pregnant women must be one part of every program; HBV vaccination programs for pregnant women are needed; large scale prospective study is also recommended to measure the extent of risks of $\mathrm{HBV}$ infection among pregnant women.

In order to reduce the spread of the virus, it is important to make public education available to the community as well as to pregnant women. In addition, other community-based studies may be used to identify potential transmission routes and to take preventive action.

\section{Limitation of the Study}

Our study used only HBsAg Sero- marker for the detection of HBV infection. Other Sero -markers other than HBsAg were not possible to use in this study. Only using HBsAg might be the reason for the under estimated prevalence of HBV infection among pregnant women which could have been obtained. Besides this the study period and participants are too small that makes generalization based on the observed result too much difficult.

\section{Abbreviation and Acronyms}

ANC - Antenatal care, HBV -Hepatitis B Virus, HBsAghepatitis B virus surface antigen HCC - heapatocellular carcinoma, MLT -medical laboratory technologist, OR-odds ratio, OPD -Out patient department, PEP - personal protective equipment, SPSS -statistical package for social science, WHO-World Health Organization

\section{Availability of Data and Material}

All materials are within the manuscript, any additional data will be shared upon request to the corresponding author.

\section{Author Contribution}

MA initiate the study concept and designed the study, KA carried out data collection, ED carried out laboratory analysis, MA \&KA supervised the data collection and laboratory analysis, MA and KA analyzed the data, MA and ED prepared the first manuscript draft, all authors read, reviewed and approved the data draft final manuscript.

\section{Ethics Approval and Consents of Participant}

This study was ethically cleared by the ethics committee of the Debre Tabor Health Science College and Debre Tabor Referral hospital. Participation was voluntary and informed verbally consent was taken from all participants before inclusion to the study. At the outset participant were briefly explained about the objective of the study, and they informed that participation is on voluntary basis and they can stop or leave from the participation at any time the study using their local language. Written consent were not acquired because all participant in Debre Tabor ANC clinic were first visitors for ANC follow up become recorded immediately on ANC registration. Therefore, considering this only verbal agreement was acquired to be included in the study. Voluntary participants who were diagnosis positive for HBV were immediately attach to ANC clinic of Debre Tabor Referral Hospital for appropriate treatment and follow up. 


\section{Consents of Publication}

Not applicable.

\section{Competing Interest}

The authors declared that they have no competing interest.

\section{Acknowledgements}

We would like to Acknowledgement the study participants, Debre Tabor Health science college Debre Tabor Referral Hospital ANC clinic staffs for their unreserved support during the study. We appreciatively acknowledge all pregnant women who participate in this study.

\section{References}

[1] Souza MT, de Pinho TLR, Santos MDC, dos Santos A, Monteiro VL, Fonsêca LMB, et al. Prevalence of hepatitis B among pregnant women assisted at the public maternity hospitals of São Luís, Maranhão, Brazil. The Brazilian Journal of Infectious Diseases. 2012; 16 (6): 517-20.

[2] Bertolini D, Pinho J, Saraceni C, Moreira R, Granato CFH, Carrilho F. Prevalence of serological markers of hepatitis B virus in pregnant women from Paraná State, Brazil. Brazilian journal of medical and biological research. 2006; 39 (8): 1083-90.

[3] Dwivedi M, Misra SP, Misra V, Pandey A, Pant S, Singh R, et al. Seroprevalence of hepatitis B infection during pregnancy and risk of perinatal transmission. Indian Journal of Gastroenterology. 2011; 30 (2): 66.

[4] Gasim GI, Murad IA, Adam I. Hepatitis B and C virus infections among pregnant women in Arab and African countries. The Journal of Infection in Developing Countries. 2013; 7 (08): 566-78.

[5] Yakubu A, Sahabi D, Saidu Y, Magaji U. Prevalence of HBsAg among prospective blood donors and pregnant women in Kebbi State, Nigeria. Nigerian Journal of Basic and Applied Sciences. 2016; 24 (1): 57-63.

[6] Juszczyk J. Clinical course and consequences of hepatitis B infection. Vaccine. 2000; 18: S23-S5.

[7] Tegegne D, Desta K, Tegbaru B, Tilahun T. Seroprevalence and transmission of Hepatitis $\mathrm{B}$ virus among delivering women and their new born in selected health facilities, Addis Ababa, Ethiopia: a cross sectional study. BMC research notes. 2014; 7 (1): 239.

[8] Fomulu NJ, Morfaw FL, Torimiro JN, Nana P, Koh MV, William T. Prevalence, correlates and pattern of Hepatitis B among antenatal clinic attenders in Yaounde-Cameroon: is perinatal transmission of HBV neglected in Cameroon? BMC pregnancy and childbirth. 2013; 13 (1): 158.

[9] Stroffolini T, Pasquini P, Mele A. HBsAg carriers among pregnant women in Italy: results from the screening during a vaccination campaign against hepatitis B. Public Health. 1988; 102 (4): 329-33.
[10] Oladimeji AA, Pius A-OI, Adekunle AE, Temi AP, Abiodun $\mathrm{O}$, Peter AO, et al. Seroprevalence of hepatitis B infection in pregnant women at the Ekiti State University Teaching Hospital, Ado-Ekiti, Southwest Nigeria. Afr J Intern Med. 2013; 2 (4): 23-5.

[11] Mac P, Suleiman A, Airiohuodion P. High prevalence of hepatitis $\mathrm{B}$ virus infection among pregnant women attending antenatal care in Central Nigeria. J Infect Dis Epidemiol. 2019; 5: 068 .

[12] Ugwuja E, Ugwu N. Seroprevalence of hepatitis B surface antigen and liver function tests among adolescents in Abakaliki, South Eastern Nigeria. The Internet Journal of Tropical Medicine. 2010; 6 (2): 1726-32.

[13] Ugbebor O, Aigbirior M, Osazuwa F, Enabudoso E, Zabayo O. The prevalence of hepatitis $\mathrm{B}$ and $\mathrm{C}$ viral infections among pregnant women. North American journal of medical sciences. 2011; 3 (5): 238.

[14] Elsheikh RM, Daak AA, Elsheikh MA, Karsany MS, Adam I. Hepatitis B virus and hepatitis $C$ virus in pregnant Sudanese women. Virology Journal. 2007; 4 (1): 104.

[15] Al-Mamari A. Determine seroprevalence and associated risk factors of HBV infection among pregnant women and it relationship with blood transfusion at Hargeisa Group Hospital, Hargeisa, Somaliland. International J Clin Virol. 2019.

[16] Yakasai IA, Ayyuba R, Abubakar I, Ibrahim S. Seroprevalence of hepatitis $\mathrm{B}$ virus infection and its risk factors among pregnant women attending antenatal clinic at Aminu Kano Teaching Hospital, Kano, Nigeria. Journal of Basic and Clinical Reproductive Sciences. 2012; 1 (1-2): 49-55.

[17] Luuse A, Dassah S, Lokpo S, Ameke L, Noagbe M, Adatara P, et al. Sero-prevalence of hepatitis B surface antigen amongst pregnant women attending an antenatal clinic, Volta region, Ghana. Journal of public health in Africa. 2016; 7 (2).

[18] Lima LHMd, Viana MC. Prevalence and risk factors for HIV, syphilis, hepatitis B, hepatitis C, and HTLV-I/II infection in low-income postpartum and pregnant women in Greater Metropolitan Vitória, Espírito Santo State, Brazil. Cadernos de saude publica. 2009; 25 (3): 668-76.

[19] Bittaye M, Idoko P, Ekele BA, Obed SA, Nyan O. Hepatitis B virus sero-prevalence amongst pregnant women in the Gambia. BMC infectious diseases. 2019; 19 (1): 259.

[20] Zenebe Y, Mulu W, Yimer M, Abera B. Sero-prevalence and risk factors of hepatitis B virus and human immunodeficiency virus infection among pregnant women in Bahir Dar city, Northwest Ethiopia: a cross sectional study. BMC infectious diseases. 2014; 14 (1): 118.

[21] Yohanes T, Zerdo Z, Chufamo N. Seroprevalence and predictors of hepatitis $\mathrm{B}$ virus infection among pregnant women attending routine antenatal care in Arba Minch Hospital, South Ethiopia. Hepatitis research and treatment. 2016; 2016.

[22] Desalegn Z, Mihret A, Beyene H, Yilma M, Seid Y, Tamiru $\mathrm{W}$, et al. Survey of hepatitis B virus infection and risk factors among pregnant women at public hospital in Ethiopia. Int $\mathrm{J}$ Biomed Res. 2016; 7 (7): 450-6.

[23] Hillary A, Julius M, Joseph N, Musa K, Ronald M, Hamson K, et al. Prevalence and factors associated with hepatitis B surface antigen positivity among women receiving antenatal care at Mbarara Regional Referral Hospital. J Trop Dis. 2019; 7: 321. 
[24] Singh A, Joshi S, Sharma YR. Prevalence of hepatitis B in pregnant women and management of babies born to Hepatitis B positive mother: A criterion based clinical audit. Journal of Patan Academy of Health Sciences. 2016; 3 (2): 23-7.

[25] Metaferia Y, Dessie W, Ali I, Amsalu A. Seroprevalence and associated risk factors of hepatitis $\mathrm{B}$ virus among pregnant women in southern Ethiopia: a hospital-based cross-sectional study. Epidemiology and health. 2016; 38.

[26] Awole M, Gebre-Selassie S. Seroprevalence of HBsAg and its risk factors amoung pregnant women in Jimma, Southwest Ethiopia. Ethiopian Journal of Health Development. 2005; 19 (1): 45-50.

[27] Molla S, Munshea A, Nibret E. Seroprevalence of hepatitis B surface antigen and anti HCV antibody and its associated risk factors among pregnant women attending maternity ward of Felege Hiwot Referral Hospital, northwest Ethiopia: a crosssectional study. Virology journal. 2015; 12 (1): 204.

[28] Seid M, Gelaw B, Assefa A. Sero-prevalence of HBV and $\mathrm{HCV}$ infections among pregnant women attending antenatal care clinic at Dessie Referral Hospital, Ethiopia. Adv Life Sci Health. 2014; 1 (2): 109-20.

[29] Tiruneh M. Seroprevalence of multiple sexually transmitted infections among antenatal clinic attendees in Gondar Health Center, Northwest Ethiopia. Ethiopian medical journal. 2008; 46 (4): 359-66.

[30] Mohebbi SR, Sanati A, Cheraghipour K, Nejad MR, Shalmani HM, Zali MR. Hepatitis C and hepatitis B virus infection: epidemiology and risk factors in a large cohort of pregnant women in Lorestan, West of Iran. Hepatitis monthly. 2011; 11 (9): 736

[31] Mortada E, Mohamed MF, Hamdi M, Ehab M, Khamiss SS, El-Karaksy H. Prevalence of hepatitis B virus infection among Egyptian pregnant women-A single center study. International journal of tropical disease \& health. 2013; 3 (2): 157-68.

[32] MacLean B, Hess RF, Bonvillain E, Kamate J, Dao D, Cosimano A, et al. Seroprevalence of hepatitis B surface antigen among pregnant women attending the Hospital for Women \& Children in Koutiala, Mali. South African Medical Journal. 2012; 102 (1).

[33] Pennap G, Osanga E, Ubam A. Seroprevalence of hepatitis B surface antigen among pregnant women attending antenatal clinic in federal medical center Keffi, Nigeria. Research Journal of Medical Sciences. 2011; 5 (2): 80-2.

[34] Lin HH, Kao JH, Chang TC, Hsu HY, Chen DS. Secular trend of age-specific prevalence of hepatitis B surface and e antigenemia in pregnant women in Taiwan. Journal of medical virology. 2003; 69 (4): 466-70.

[35] Collenberg E, Ouedraogo T, Ganamé J, Fickenscher H, Kynast-Wolf G, Becher $\mathrm{H}$, et al. Seroprevalence of six different viruses among pregnant women and blood donors in rural and urban Burkina Faso: a comparative analysis. Journal of medical virology. 2006; 78 (5): 683-92.

[36] Buseri FI, Muhibi MA, Jeremiah ZA. Sero-epidemiology of transfusion-transmissible infectious diseases among blood donors in Osogbo, south-west Nigeria. Blood Transfusion. 2009; 7 (4): 293. 